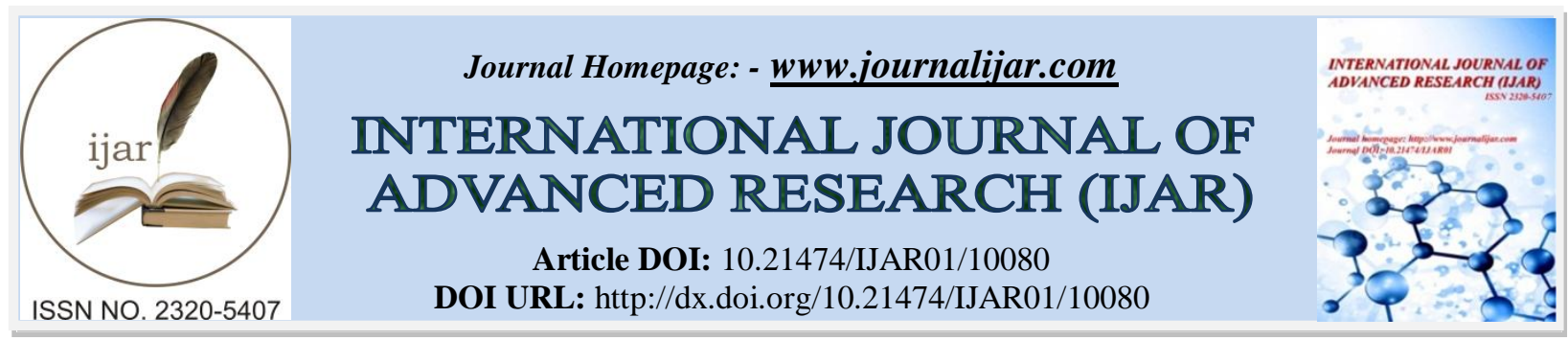

RESEARCH ARTICLE

\title{
THE EFFECTIVENESS OF LOCAL ATORVASTATIN IN THE TREATMENT OF MODERATE PERIODONTITIS.
}

\author{
Mayada M. khoder ${ }^{1}$, Germeen N.S. Girgis ${ }^{2}$, Mohamed M. Anees ${ }^{3}$ and Jilan M. Youssef ${ }^{4}$. \\ 1. (B.D.S), Faculty of Dentistry, Mansoura University. \\ 2. Lecturer of pharmaceutics, Faculty of Pharmacy - Mansoura University. \\ 3. Ass. Professor of Oral Medicine and Periodontology, Faculty of Dentistry, Mansoura University. \\ 4. Professor of Oral Medicine and Periodontology, Faculty of Dentistry, Mansoura University.
}

\section{Manuscript Info}

.........................

Manuscript History

Received: 14 September 2019

Final Accepted: 16 October 2019

Published: November 2019

Key words:-

Chronic periodontitis, Atorvastatin, local drug delivery, osteocalcin, gingival crevicular fluid.

\section{Abstract}

Background: Chronic periodontitis is an infectious disease resulting in inflammation within the supporting structures of teeth, loss of attachment and bone resorption. Atorvastatin is a potent synthetic competitive inhibitor of Hydroxy Methyl Glutaryl-Co enzyme A reductase. It has a favourable effect on bone, as well as immunomodulatory effect.

Aim: The aim of this study was to determine the effectiveness of local Atorvastatin as an adjunct to scaling and root planning in the treatment of chronic periodontitis.

Subjects and method: Fivteen chronic periodontits patients were involved in this study. Split mouth design was utilized. Clinical parameters (Gingival Index, Plaque Index, Bleeding On Probing, Clinical Attachment Loss, probing Pocket Depth) were recorded at baseline and after eight weeks after treatment. Gingival crevicular fluid samples were collected at baseline and eight weeks after treatment from both test and control sites, and osteocalcin level was assessed. All patients received scaling and root planning, the test sites only were locally injected with atorvastatin gel.

Results: Clinical parameters of test sites showed very highly significant reduction in at $\mathrm{p}<0.001^{* *}$ versus control sites eight weeks after treatment. Test sites only showed significant reduction in osteocalcin level in gingival crevicular fluid at $\mathrm{p}=0.005^{*}$ versus control sites, eight weeks after treatment.

Conclusion: Locally applicated Atorvastain adjunctive with scaling and root planning could be effective in treatment of chronic periodontitis.

Copy Right, IJAR, 2019,. All rights reserved.

\section{Introduction:-}

Periodontal diseases are a group of conditions affecting the supporting structures of the dentition. ${ }^{1}$ Its pathogenesis is associated with formation of microbial colonies within subgingival plaque. ${ }^{2}$ According to Socransky's classification, plaque bacteria are classified into six related complexes - yellow, green, violet, orange, red and

Corresponding Author:-Mayada M.khoder.

Address:-(B.D.S), Faculty of Dentistry, Mansoura University. 
Actinomyces. $^{3}$ It is known that, the diverse plaque bacteria colonize in a certain order through cell-to-cell coaggregation. ${ }^{4}$

The primary goal of periodontal therapy is to preserve the natural dentition, by arresting the chronic inflammatory process, that results in loss of both periodontal attachment and alveolar bone. ${ }^{5}$

Scaling and root planing (SRP) is the major part in periodontal therapy. Locally adminstrated agents can be effective in treatment of moderate periodontitis, as adjunctive to $\mathrm{SRP}^{6}$. Local application into periodontal pocket could be very advantageous, in terms of applying drug concentration directly in the action site, and in preventing systemic side effects. ${ }^{7}$ It can be also safely used in medically compromised patients for whom surgery is not an option. ${ }^{8}$

Newer trend materials used in local delivery include taurolidine, alendronate, basic fibroblast growth factor, ipriflavone, herbal extracts, statins. ${ }^{9}$ Statins are the most commonly cholesterol-lowering agents used to manage and prevent cardiovascular and coronary heart diseases. ${ }^{10}$ Apart from their lipopenic function, statins have shown secondary effects including anti-inflammatory, immunomodulatory, antioxidant, antithrombotic, and endothelium stabilization actions ${ }^{11}$, as well as promotion of angiogenesis and osteoblastic differentiation ${ }^{12}$.

The lipophilic statins as Atorvastatin (ATV) seem to be more effective than the hydrophilic statins in bone protection. ${ }^{13}$ Atorvastatin (ATV) is a specific competitive inhibitors of 3-hydroxy-2-methyl-glutaryl coenzyme A (HMGCoA) reductase. ${ }^{14-16}$ ATV could reduce the migration and infiltration of the leukocytes and T-cell activation. ${ }^{10}$ ATVinhibits NF-kappa B activation, which lead to inhibition of a lot of chemokines as TNF- $\gamma .{ }^{17,18}$ The anti-inflammatory activity of ATV is evidenced by the reduced expression of TNF- $\alpha$, IL- $1 \beta,-6$ and -8 , and increase of IL-10. ${ }^{19}$ ATV improves the gingival oxidative stress, reestablishing reduced glutathione, superoxide dismutase and catalse levels on periodontium. ${ }^{20,21}$

Atorvastatin could increase angiogenesis and the expression of messenger RNA (mRNA) of bone morphogenetic protein-2 (BMP-2) in osteoblasts. ${ }^{22}$ The antiresorptive effect of the ATV seems to be a result of the increased production of mRNA of osteoprotegerin (OPG) by osteoblasts. ${ }^{23}$ This effect could be also related to its role in decreasing the level of IL- $6 .{ }^{24}$

One of the most essential diagnostic measures in periodontitis is gingival crevicular fluid (GCF). Its importance result from its proteins and peptides contents which arise from the host inflamed tissues. It can indicate the health status at localized areas. Therefore, it could be potential biomarkers for periodontitis. The GCF biomarkers include; host derived enzymes such as MMP, elastase, beta-glucuronidase, and aspartate aminotransferase, inflammatory mediators and products biomarkers such as prostaglandin E2, TNF- $\alpha$, interferon- $\alpha$, substance-P, monocyte chemoattractant protein, and cytokines. It also, includes bone turnover markers such as; alkaline phosphatase (ALP), cathepsin B, osteocalcin (OC), pyridinoline cross-linked carboxyterminal telopeptide of type I, and Collagen ${ }^{25,26}$.

Osteocalcin; an abundant non-collagenous bone matrix protein $^{27}$ is secreted mainly from matured osteoblasts ${ }^{27}$. Osteocalcin also can be detected in GCF. It may be derived from circulating level, and may be localized secreted from active osteoblasts either or as a result of alveolar bone resorption ${ }^{28,29}$. As, OC levels in GCF can indicate the inflammation, therefore, $\mathrm{OC}$ can be used as a bone turnover marker in periodontitis ${ }^{30,31}$.

\section{Patients and Methods:-}

\section{Patient selection}

This study was conducted on 15 patients attending at the Department of Oral Medicine and Periodontology, Faculty of Dentistry, Mansoura University. The studied individuals consisted of systemically healthy 13 females and 2 males, aged from 35 to 50 years. They were diagnosed as having moderate periodontitis (clinical attachment level 3 $4 \mathrm{~mm}) .^{32}$ Patients were excluded if they were suffering from metabolic bone diseases, allergy to the statins, or if they had periodontal therapy in the preceding 3 months. Users of tobacco, and pregnant or lactating women were also excluded. All the participants clearly understood the purpose of the study. Approval of this study was obtained from the Faculty of Dentistry, Mansoura University.

\section{Study design:}

Split mouth design was utilized; in each patient, one site was randomly assigned to study group and the other contralateral site to control group. At baseline, proper case history, clinical examination and radiographic evaluation were done to select the patients. Periodontal parameters were recorded and gingival crevicular fluid (GCF) samples 
were collected from both test and control sites, and periodontal parameters were recorded. Then, patients received full mouth scaling and root planing with ultrasonic scaler and manual instruments under local anaethesia. ATV gel was injected into test site pockets using syringe with blunt cannula. The patients only received general oral hygiene instructions. After eight weeks, periodontal parameters were recorded and GCF samples were collected again from both test and control sites.

\section{Clinical assessment: \\ Periodontal parameters:}

The following parameters: gingival index (GI), plaque index (PI), bleeding on probing index (BOP), probing pocket depth (PPD) and clinical attachment loss (CAL) were measured at the basline \& after eight weeks of treatment for both groups.

\section{Gingival crevicular fluid collection:}

GCF samples were collected from all individuals at baseline, and eight weeks after treatment from both test and control sites to evaluate the level of osteocalcin. All supragingival plaque was removed. The tooth surfaces were cleaned from blood or any debris, dried by air syringe and isolated from saliva by cotton rolls. Sterile paper points were inserted into pocket until mild resistance were felt, and left for 30 seconds. Paper points contaminated with blood or saliva were discarded. Paper points were immediately placed after sample collection in $1.8 \mathrm{ml}$ eppendorf tube which containsed $250 \mu$ phosphate buffered solution, $\mathrm{PH} 6$ and stored at $-80^{\circ} \mathrm{C}^{33}$ at Department of Microbiology, Faculty of Medicine, Mansoura University.

\section{Laboratory assessment:}

\section{Formulation of $1.2 \%$ ATV Gel:}

Atorvastatin gel was prepared as described by Thylin et al. ${ }^{34}$ Briefly, methylcellulose gel was prepared by adding the required amount of distilled water to an accurately weighed amount of methylcellulose. The vial was heated to $50^{\circ} \mathrm{C}$ - $60^{\circ} \mathrm{C}$ and agitated using a mechanical shaker to obtain a clear solution. A weighed amount of ATV was added to the above solution and dissolved completely to obtain a homogeneous phase of polymer, solvent, and drug. Thus, the ATV gel was prepared with a concentration of $1.2 \%$. The placebo gel contained the same methylcellulose gel without the ATV added.

\section{Osteocalin assessment:}

Osteocalcin level in gingival crevicular fluid was measured using ELISA kit (Elabscience). This ELISA kit used Sandwich ELISA as the method. The micro ELISA plate provided in this kit had been precoated with an antibody specific to OC/BGP. Standards or samples were added to the appropriate micro ELISA plate wells and combined with the specific antibody. Then a biotinylated detection antibody specific for OC/BGP and Avidin-Horseradish Peroxidase (HRP) conjugate was added to each micro plate well successively and incubated. Free components were washed away. The substrate solution was added to each well. Only those wells that contain OC/BGP, biotinylated detection antibody and Avidin-HRP conjugate were appeared blue in color. The enzyme-substrate reaction was terminated by the addition of a sulphuric acid solution and the color turned yellow. The optical density (OD) was measured spectrophotometrically at a wave length of $450 \mathrm{~nm} \pm 2 \mathrm{~nm}$. The OD value was proportional to the concentration of OC/BGP. The concentration of OC/BGP was calculated in the samples by comparing the OD of the samples to the standard curve.

\section{Results:-}

Concerning test sites at baseline GI, PI, BOP, PPD, CAL, OC were 1.71 $\pm 0.26,1.82 \pm 0.27,0.97 \pm 0.08,4.05 \pm 0.28$, $4.20 \pm 0.91,2.19 \pm 0.30$, respectively. While eight weeks after treatment the values became $0.543 \pm 0.16,0.42 \pm 0.12$, $0.36 \pm 0.18,2.35 \pm 0.50,2.61 \pm 0.78,1.86 \pm 0.27$, respectively. Regarding control sites at base line, GI, PI, BOP, PPD, CAL, OC were $1.69 \pm 0.31,1.81 \pm 0.29,0.95 \pm 0.10,4.01 \pm 0.29,3.92 \pm 0.83,2.42 \pm 0.54$, respectively. Eight weeks after treatment, the values became $1.13 \pm 0.33,0.89 \pm 0.19,0.67 \pm 0.18,3.33 \pm 0.38,3.35 \pm 0.68,2.41 \pm 0.64$, respectively. At baseline, there was no statistically significant difference between test and control sites regarding clinical parameters and lab assessment. Thus, clinical parameters and laboratory assessment of both sites were improved significantly eight weeks after treatment. Moreover, the test sites were significantly improved versus the control sites regarding the same parameters. 


\section{Discussion:-}

Periodontitis is a multi-factorial disease, resulting in the destruction of periodontal tissues, bone resorption and tooth loss. ${ }^{35}$ Non-surgical periodontal therapy in moderate periodontitis is an effective treatment, ${ }^{36}$ where local drug delivery is one of the best adjunctives. ${ }^{37}$ ATV inhibits the secretion of cytokines in chronic inflammatory diseases. The effect of statins on bone metabolism can be summarized into three major mechanisms; promotion of osteogenesis, suppression of osteoblast apoptosis and inhibition of osteoclastogenesis. ${ }^{38}$

Osteocalcin is the greatest plentiful non-collagenous protein. It is mostly secreted from osteoblasts, odontoblasts and hypertrophic chondrocytes. Osteocalcin play a critical role in bone formation and turnover. It is also supposed to induce bone resorption, and induce osteoclast progenitor cells differentiation, that may result in negative role in bone formation. Osteocalcin is currently an effective marker of bone turnover when resorption and formation are coupled and is a particular marker of bone formation when formation and resorption are uncoupled. ${ }^{39-41}$

All pregnant and lactating women were excluded due to increased susceptibility to periodontal infection, hormonal changes, and alterations in the immune system. ${ }^{42,43}$ Smokers were also excluded, as smoking increase proinflammatory circulating cytokine levels as tumor necrosis factor-alpha (TNF- $\alpha$ ), and alteres the collagen metabolism and wound healing, resulting in increasing the subgingival infection. ${ }^{44,45}$ Patients who had taken systemic antibiotic for the last three months before study were also excluded, due to its effect on potential periodontopathic bacteria. ${ }^{46}$ Additionally, diabetic patients were excluded, as diabetes alters the efficancy of the immune system. ${ }^{47,48}$

Split mouth design was applied because of its advantages. It requires small sample size, as each patient acts as his/her own control. Also, much of the inter-subject variability was removed, resulting in increased study credibility. $^{49}$

At baseline, there were no significant differences in the values of clinical parameters (PI, GI, PPD, CAL, and BOP) between test and control sites. After eight weeks of treatment, both test \& control sites showed significant reduction in the mean values of all periodontal parameters, when it was compared with its value at baseline. These results came in agreement with Carvalho el al. ${ }^{50}$, and Colombo et al. ${ }^{51}$ they reported that SRP with regular motivation of oral hygiene measures, resulted in significant reduction of all periodontal parameters (PPD, CAL, BOP). Biofilm disruption and calculus removal through supra and subgingival mechanical instrumentation, result in an overwhelming reduction of periodontal pathogens and reestablishment of a healthy compatible microbiota. ${ }^{51}$ control by toothbrushing, combined with the removal of inter-dental plaque achieving ideal plaque control by toothbrushing, combined with the removal of inter-dentalplaque achieving ideal plaque control by toothbrushing, combined with the removal of inter-dental plaqueThese result from ideal plaque control by tooth brushing accombined with interdental plaquThe clinical benefits of supra and subgingival mechanical instrumentation are due to biofilm disruption and calculus removal, resulting in overwhelming reduction of periodontal pathogens and re-establishment of a healthy comaptible microbiota ${ }^{51}$

After treatment, there were highly significant differences in the mean value of all clinical parameters between test and control group when compared with their values at baseline. These results came in agreement with Ambrósio et al. ${ }^{52}$, Shah el al. ${ }^{53}$ and Bertl el al. ${ }^{54}$; they found that there was a significant lowering in pocket depth of test group compared with control group. Also, CAL gain was significantly improved in test group when compared with control group. BOP showed significant reduction in test group versus control one. Pradeep et al ${ }^{55}$ found that reduction in PI was more significant in test group than control group after treatment.

Additionally, test site showed a significant reduction in all periodontal parameters (GI, PI, PPD, BOP, CAL) versus control group. These results came in agreement with Martande el $\mathrm{al}^{35}$, and sinjab et al. ${ }^{56}$ they found that there was more improvement in clinical parameters (PI, PPD, CAL) of test group after locally application of statins as adjunctive to mechanical SRP than control group. Additionally, Rosenberg et al. ${ }^{57}$ reported that one month using of $2 \%$ ATV dentifrice for periodontitis patients, showed greater significant reduction in BOP and GI. Fajardo et al. reported that there was a reduction in mobility and probing pocket depth in patients treated with ATV. ${ }^{58}$ Pradeep et al. ${ }^{55,59}$ recorded that local delivery of ATV administration as adjunctive to SRP in treatment of chronic periodontitis patients result in reduction of bleeding on probing. 
Statins also could inhibit major histocompability complex class II (MHC-II) molecules, which are directly involved in the activation of T-lymphocytes and in the control of the immune response through antigen presentation. ${ }^{60}$ Statins could suppress the expression of MMP mRNA, which may be a result of isoprenoid intermediates reduction. ${ }^{61}$

Atovastatin might have the ability to influence the level of tissue destruction in periodontal disease. It could interact with the immune response of the host, and inhibit adhesion and extravasation of leukocytes to inflammation sites. This interaction resulting in diminished co-stimulation of T cells and reduction of inflammatory cytokines (IL-1 $\beta$, IL-6 and TNF- $\alpha) .{ }^{62-65}$ Thus, suggesting that ATV may have anti-inflammatory effect on periodontal tissue. ${ }^{66}$

Regarding the laboratory assessment of osteocalcin level in GCF at baseline, no statistically significant difference was found between test \& control sites. These results came in agreement with other studies that detected OC in GCF of periodontal diseased patients, and they added, there is a correlation between osteocalcin levels in GCF and patient periodontal status. $^{30,33,67,68}$

High levels of osteocalcin in GCF of chronic periodontitis sites may be related to the severity of breakdown and/or repair of alveolar bone. During active bone resorption, osteocalcin is mostly released from the extracellular matrix into the GCF. ${ }^{69}$ Also, proteolytic enzymes secreted from the host and pathogenic microorganisms will also play a role in the generation of osteocalcin fragments. ${ }^{70}$ It was suggested that osteocalcin induce the recruitment and differentiation of circulating monocytes and osteoclast precursors, indicating its role on resorption of bone. ${ }^{71-74}$

Eight weeks after treatment, OC level was significantly decreased in test sites, but there was no statistically significant decreses in control sites versus its level at baseline.

To the best of our knowledge, no previous study assessed ATV effect in correlation with gingival crevicular fluid osteocalcin. Although a lot of researches evaluated statins effect on treatment of periodontitis, but those depend on radiographic evaluation of their patients or serum osteocalcin. So, no previous studies agree or disagree with our results. Furthermore, they evaluated their patients six or nine months after treatment. So, we cannot compare our results with those studies.

Atorvastatin could regulate different aspects of bone metabolism such as OC which are important markers for bone differentiation and mineralization. ${ }^{75}$ The role of statins as immunomodulator could be a part of its effect on bone formation, as it could block the synthesis of important isoprenoid intermediates ${ }^{63,76}$ which result in the osteocalst cells formation with wrinkled margins $\mathrm{s}^{61,77}$.

Thus, ATV could be used not only for promising treatment of periodontitis, but, also could be tried to preserve bone especially for those who are liable to develop severe forms of the disease either due to systemic diseases, genetic or immune disorders.

\section{Conclusion:-}

There were greater improvements in clinical parameters of chronic periodontitis patients when locally delivered ATV was used as adjunctive to scaling and root planning for the treatment of chronic periodontitis.

\section{References:-}

1. Pejčić A, Obradović R, Kesić L, Kojović D. Smoking and periodontal disease: a review. Med Biol. 2007;14(2):53-9.

2. Kamma JJ, Slots J. Herpesviral-bacterial interactions in aggressive periodontitis. J Clin Periodontol. 2003;30(5):420-426.

3. Socransky SS, Haffajee AD, Cugini MA, Smith C, Kent RL. Microbial complexes in subgingival plaque. J Clin Periodontol. 1998;25(2):134-144.

4. Kolenbrander PE, Andersen RN, Blehert DS, Egland PG, Foster JS, Palmer RJ. Communication among oral bacteria. Microbiol Mol Biol Rev. 2002;66(3):486-505.

5. Sanz I, Alonso B, Carasol M, Herrera D, Sanz M. Nonsurgical treatment of periodontitis. J Evid Based Dent Pract. 2012;12(3):76-86.

6. Dentino A, Lee S, Mailhot J, Hefti AF. Principles of periodontology. Periodontol 2000. 2013;61(1):16-53. 
7. Schwach-Abdellaoui K, Vivien-Castioni N, Gurny R. Local delivery of antimicrobial agents for the treatment of periodontal diseases. Eur J Pharm Biopharm. 2000;50(1):83-99.

8. Garg S. Local Drug Delivery Systems as an Adjunct to Cure Periodontitis-The Novel Dental Applicant. Pharm Methods. 2015;6(1):1.

9. Pattanshetti JI, Tiwari I, Singh G, Tazyeen F, Parihar AS, Khare N. Local Drug Delivery Modalities in Treatment of Periodontitis: A Review. J Int Oral Health. 2016;8(2):296.

10. Gazzerro P, Proto MC, Gangemi G, Malfitano AM, Ciaglia E, Pisanti S, et al. Pharmacological actions of statins: a critical appraisal in the management of cancer. Pharmacol Rev. 2012;64(1):102-146.

11. Landmesser U, Bahlmann F, Mueller M, Spiekermann S, Kirchhoff N, Schulz S, et al. Simvastatin versus ezetimibe pleiotropic and lipid-lowering effects on endothelial function in humans. Circulation. 2005;111(18):2356-2363.

12. Maeda T, Matsunuma A, Kurahashi I, Yanagawa T, Yoshida H, Horiuchi N. Induction of osteoblast differentiation indices by statins in MC3T3-E1 cells. J Cell Biochem. 2004;92(3):458-471.

13. Uzzan B, Cohen R, Nicolas P, Cucherat M, Perret G-Y. Effects of statins on bone mineral density: a metaanalysis of clinical studies. Bone. 2007;40(6):1581-1587.

14. Henwood JM, Heel RC. Lovastatin. Drugs. 1988;36(4):429-454.

15. Kishida Y, Naito A, Iwado S, Terahara A, Tsujita Y. Research and development of pravastatin. Yakugaku Zasshi. 1991;111(9):469-487.

16. Todd PA, Goa KL. Simvastatin. Drugs. 1990;40(4):583-607.

17. Martín-Ventura JL, Blanco-Colio LM, Gómez-Hernández A, Muñoz-García B, Vega M, Serrano J, et al. Intensive treatment with atorvastatin reduces inflammation in mononuclear cells and human atherosclerotic lesions in one month. Stroke. 2005;36(8):1796-1800.

18. Li J, Li J-J, He J-G, Nan J, Guo Y, Xiong C. Atorvastatin Decreases C-Reactive Protein-Induced Inflammatory Response in Pulmonary Artery Smooth Muscle Cells by Inhibiting Nuclear Factor- $\kappa B$ Pathway. Cardiovasc Ther. 2010;28(1):8-14.

19. Sousa LH, Linhares EV, Alexandre JT, Lisboa MR, Furlaneto F, Freitas R, et al. Effects of Atorvastatin on Periodontitis of Rats Subjected to Glucocorticoid-induced Osteoporosis. J Periodontol. 2016;(00):1-17.

20. de Araújo Júnior RF, Souza TO, de Moura LM, Torres KP, de Souza LB, Alves M do SCF, et al. Atorvastatin decreases bone loss, inflammation and oxidative stress in experimental periodontitis. PloS One. 2013;8(10):e75322.

21. Dalcico R, de Menezes AM, Deocleciano OB, Oriá RB, Vale ML, Ribeiro RA, et al. Protective mechanisms of simvastatin in experimental periodontal disease. J Periodontol. 2013;84(8):1145-1157.

22. Mundy G, Garrett R, Harris S, Chan J, Chen D, Rossini G, et al. Stimulation of bone formation in vitro and in rodents by statins. Science. 1999;286(5446):1946-1949.

23. Viereck V, Gründker C, Blaschke S, Frosch K-H, Schoppet M, Emons G, et al. Atorvastatin stimulates the production of osteoprotegerin by human osteoblasts. J Cell Biochem. 2005;96(6):1244-1253.

24. Chang B, Yang J, Li H, Lu S, Chen L, Fang P. Effects of atorvastatin on bone metabolism and bone mineral density in Wistar rats. Pharm- Int J Pharm Sci. 2011;66(7):535-537.

25. AlRowis R, AlMoharib HS, AlMubarak A, Bhaskardoss J, Preethanath RS, Anil S. Oral fluid-based biomarkers in periodontal disease-Part 2. Gingival crevicular fluid. J Int Oral Health JIOH. 2014;6(5):126.

26. Kinney JS, Ramseier CA, Giannobile WV. Oral Fluid-Based Biomarkers of Alveolar Bone Loss in Periodontitis. Ann N Y Acad Sci. 2007 Mar 1;1098(1):230-51.

27. Neve A, Corrado A, Cantatore FP. Osteocalcin: Skeletal and extra-skeletal effects. J Cell Physiol. 2013;228(6):1149-1153.

28. Lee AJ, Walsh TF, Hodges SJ, Rawlinson A. Gingival crevicular fluid osteocalcin in adult periodontitis. J Clin Periodontol. 1999;26(4):252-256.

29. Ducy P, Schinke T, Karsenty G. The osteoblast: a sophisticated fibroblast under central surveillance. Science. 2000;289(5484):1501-1504.

30. Bullon P, Goberna B, Guerrero JM, Segura JJ, Perez-Cano R, Martinez-Sahuquillo A. Serum, saliva, and gingival crevicular fluid osteocalcin: their relation to periodontal status and bone mineral density in postmenopausal women. J Periodontol. 2005;76(4):513-519.

31. Bullon P, Chandler L, Segura Egea JJ, Perez Cano R, Martinez Sahuquillo A. Osteocalcin in serum, saliva and gingival crevicular fluid: their relation with periodontal treatment outcome in postmenopausal women. Med Oral Patol Oral Cir Bucal Internet. 2007;12(3):193-197.

32. Armitage GC. Development of a classification system for periodontal diseases and conditions. Ann Periodontol. 1999;4(1):1-6. 
33. Kunimatsu K, Mataki S, Tanaka H, Mine N, Kiyoki M, Hosoda K, et al. A cross-sectional study on osteocalcin levels in gingival crevicular fluid from periodontal patients. J Periodontol. 1993;64(9):865-869.

34. Thylin MR, McConnell JC, Schmid MJ, Reckling RR, Ojha J, Bhattacharyya I, et al. Effects of simvastatin gels on murine calvarial bone. J Periodontol. 2002;73(10):1141-1148.

35. Martande SS, Kumari M, Pradeep AR, Singh SP, Suke DK. Comparative evaluation of efficacy of subgingivally delivered $1.2 \%$ Atorvastatin and $1.2 \%$ Simvastatin in the treatment of intrabony defects in chronic periodontitis: a randomized controlled trial. J Dent Res Dent Clin Dent Prospects. 2017;11(1):18.

36. Mlachkova AM, Popova CL. Dental Investigations: Efficiency of Nonsurgical Periodontal Therapy in Moderate Chronic Periodontitis. Folia Med (Plovdiv). 2014;56(2):109-115.

37. Garg T, Bilandi A, Kapoor B, Kumar S, Joshi R. Scaffold: Tissue engineering and regenerative medicine. Int Res J Pharm. 2011;2(12):37-42.

38. Zhang Y, Bradley AD, Wang D, Reinhardt RA. Statins, bone metabolism and treatment of bone catabolic diseases. Pharmacol Res. 2014;88:53-61.

39. Taba Jr M, Kinney J, Kim AS, Giannobile WV. Diagnostic biomarkers for oral and periodontal diseases. Dent Clin North Am. 2005;49(3):551.

40. Ram VS, Parthiban US, Mithradas N, Prabhakar R. Bonebiomarkers in periodontal disease: a review article. J Clin Diagn Res JCDR. 2015;9(1):ZE07.

41. Daily ZA, Mohammed AN. Periodontal Health Status and Assessment of Osteocalcin levels in Saliva of Diabetic Patients and Systemically Healthy Persons (Comparative study). J Baghdad Coll Dent. 2017;29(1):8995.

42. Mascarenhas P, Gapski R, Al-Shammari K, Wang H-L. Influence of sex hormones on the periodontium. J Clin Periodontol. 2003;30(8):671-681.

43. Lieff S, Boggess KA, Murtha AP, Jared H, Madianos PN, Moss K, et al. The oral conditions and pregnancy study: periodontal status of a cohort of pregnant women. J Periodontol. 2004;75(1):116-126.

44. Zambon JJ, Grossi SG, Machtei EE, Ho AW, Dunford R, Genco RJ. Cigarette smoking increases the risk for subgingival infection with periodontal pathogens. J Periodontol. 1996;67:1050-1054.

45. Makino A, Yamada S, Okuda K, Kato T. Nicotine involved in periodontal disease through influence on cytokine levels. FEMS Immunol Med Microbiol. 2008;52(2):282-286.

46. Slots J $\varnothing$, Ting M. Systemic antibiotics in the treatment of periodontal disease. Periodontol 2000. 2002;28(1):106-176.

47. Manouchehr-Pour M, Spagnuolo PJ, Rodman HM, Bissada NF. Comparison of neutrophil chemotactic response in diabetic patients with mild and severe periodontal disease. J Periodontol. 1981;52(8):410-415.

48. McMullen JA, Dyke TV, Horoszewicz HU, Genco RJ. Neutrophil chemotaxis in individuals with advanced periodontal disease and a genetic predisposition to diabetes mellitus. J Periodontol. 1981;52(4):167-173.

49. Pandis N, Walsh T, Polychronopoulou A, Katsaros C, Eliades T. Split-mouth designs in orthodontics: an overview with applications to orthodontic clinical trials. Eur J Orthod. 2013;35(6):783-789.

50. Carvalho LH, D'ávila GB, Leao A, Haffajee AD, Socransky SS, Feres M. Scaling and root planing, systemic metronidazole and professional plaque removal in the treatment of chronic periodontitis in a Brazilian population. J Clin Periodontol. 2004;31(12):1070-1076.

51. Colombo APV, Teles RP, Torres MC, Rosalém Jr W, Mendes MCS, Souto RM, et al. Effects of non-surgical mechanical therapy on the subgingival microbiota of Brazilians with untreated chronic periodontitis: 9-month results. J Periodontol. 2005;76(5):778-784.

52. Ambrósio LMB, Rovai ES, Sendyk DI, Holzhausen M, Pannuti CM. Does the adjunctive use of statins provide additional benefits to nonsurgical periodontal treatment? A systematic review and meta-analysis. J Periodontal Res. 2017;

53. Shah M, Muley P, Muley A. Are statins worthy for treatment of periodontitis? A systematic review and metaanalysis. Adv Hum Biol. 2017;7(1):8.

54. Bertl KB Bj orn KliKristina, Arlinda Parllaku, Nikolaos Pandis, $\mathrm{K}^{\circ}$ are Buhlin. The effect of local and systemic statin use as an adjunct to non-surgical and surgical periodontal therapy-A systematic review and metaanalysis. J Dent.

55. Pradeep AR, Kumari M, Rao NS, Martande SS, Naik SB. Clinical efficacy of subgingivally delivered $1.2 \%$ atorvastatin in chronic periodontitis: A randomized controlled clinical trial. J Periodontol. 2013;84(7):871-879.

56. Sinjab K, Zimmo N, Lin G-H, Chung M-P, Shaikh L, Wang H-L. The Effect of Locally Delivered Statins on Treating Periodontal Intrabony Defects: A Systematic Review and Meta-Analysis. J Periodontol. 2017;88(4):357-367. 
57. Rosenberg DR, Andrade CX, Chaparro AP, Inostroza CM, Ramirez V, Mestres J, et al. Short-term effects of $2 \%$ atorvastatin dentifrice as an adjunct to periodontal therapy: a randomized double-blind clinical trial. J Clin Periodontol. 2015;42:3.

58. Fajardo ME, Rocha ML, Sánchez-Marin FJ, Espinosa-Chávez EJ. Effect of atorvastatin on chronic periodontitis: a randomized pilot study. J Clin Periodontol. 2010;37(11):1016-1022.

59. Pradeep AR, Rao NS, Bajaj P, Kumari M. Efficacy of subgingivally delivered simvastatin in the treatment of patients with type 2 diabetes and chronic periodontitis: a randomized double-masked controlled clinical trial. $\mathbf{J}$ Periodontol. 2013;84(1):24-31.

60. Saxlin T, Suominen-Taipale L, Knuuttila M, Alha P, Ylöstalo P. Dual effect of statin medication on the periodontium. J Clin Periodontol. 2009;36(12):997-1003.

61. Marin LM. Efectos pleitrópicos de los fármacos hipolipemiantes. Cardiovasc RISK FACTORS. 2001;10(3):145-155.

62. Liao JK, Laufs U. Pleiotropic effects of statins. Annu Rev Pharmacol Toxicol. 2005;45:89.

63. Sakoda K, Yamamoto M, Negishi Y, Liao JK, Node K, Izumi Y. Simvastatin decreases IL-6 and IL-8 production in epithelial cells. J Dent Res. 2006;85(6):520-523.

64. Fentoğlu Ö, Kırzıoğlu FY, Özdem M, Kocak H, Sütçü R, Sert T. Proinflammatory cytokine levels in hyperlipidemic patients with periodontitis after periodontal treatment. Oral Dis. 2012;18(3):299-306.

65. Suresh S, Narayana S, Jayakumar P, Sudhakar U, Pramod V, others. Evaluation of anti-inflammatory effect of statins in chronic periodontitis. Indian J Pharmacol. 2013;45(4):391.

66. Estanislau IMG, Terceiro IRC, Lisboa MRP, Teles P de B, Carvalho R de S, Martins RS, et al. Pleiotropic effects of statins on the treatment of chronic periodontitis-a systematic review. Br $\mathrm{J}$ Clin Pharmacol. 2015;79(6):877-885.

67. Nakashima K, Roehrich N, Cimasoni G. Osteocalcin, prostaglandin E2 and alkaline phosphatase in gingival crevicular fluid: their relations to periodontal status. J Clin Periodontol. 1994;21(5):327-333.

68. Giannobile WV, Lynch SE, Denmark RG, Paquette DW, Fiorellini JP, Williams RC. Crevicular fluid osteocalcin and pyridinoline cross-linked carboxyterminal telopeptide of type I collagen (ICTP) as markers of rapid bone turnover in periodontitis. J Clin Periodontol. 1995;22(12):903-910.

69. Baumgrass R, Williamson MK, Price PA. Identification of peptide fragments generated by digestion of bovine and human osteocalcin with the lysosomal proteinases cathepsin B, D, L, H, and S. J Bone Miner Res. 1997;12(3):447-455.

70. Eley BM, Cox SW. Cathepsin B/L-, elastase-, tryptase-, trypsin-and dipeptidyl peptidase IV-like activities in gingival crevicular fluid: correlation with clinical parameters in untreated chronic periodontitis patients. J Periodontal Res. 1992;27(1):62-69.

71. Hauschka PV, Lian JB, Cole DE, Gundberg CM. Osteocalcin and matrix Gla protein: vitamin K-dependent proteins in bone. Physiol Rev. 1989;69(3):990-1047.

72. Villafán-Bernal JR, SáNcHEz-ENRíqUEz S, Muñoz-Valle JF. Molecular modulation of osteocalcin and its relevance in diabetes. Int J Mol Med. 2011;28(3):283-293.

73. Mundy GR, Poser JW. Chemotactic activity of the $\gamma$-carboxyglutamic acid containing protein in bone. Calcif Tissue Int. 1983;35(1):164-168.

74. Glowacki J, Lian JB. Impaired recruitment and differentiation of osteoclast progenitors by osteocalcin-deplete bone implants. Cell Differ. 1987;21(4):247-254.

75. Liu S, Bertl K, Sun H, Liu Z-H, Andrukhov O, Rausch-Fan X. Effect of simvastatin on the osteogenetic behavior of alveolar osteoblasts and periodontal ligament cells. Hum Cell. 2012;25(2):29-35.

76. Mennickent S, Bravo M, Calvo C, Avello M. Efectos pleiotrópicos de las estatinas. Rev Médica Chile. 2008;136(6):775-782.

77. Fisher JE, Rogers MJ, Halasy JM, Luckman SP, Hughes DE, Masarachia PJ, et al. Alendronate mechanism of action: geranylgeraniol, an intermediate in the mevalonate pathway, prevents inhibition of osteoclast formation, bone resorption, and kinase activation in vitro. Proc Natl Acad Sci. 1999;96(1):133-138. 